\title{
Nefazodone in Psychotic Unipolar and Bipolar Depression: A Retrospective Chart Analysis and Open Prospective Study on Its Efficacy and Safety versus Combined Treatment with Amitriptyline and Haloperidol
}

\author{
Heinz Grunze ${ }^{a}$ Alain Marcuse ${ }^{a}$ Lars O. Schärer ${ }^{b}$ Christoph Born ${ }^{b}$ \\ J örg Walden ${ }^{b}$ \\ Departments of Psychiatry, aLMU Munich, Munich, and bUniversity of Freiburg, Freiburg, Germany
}

\section{Key Words}

Nefazodone · Amitriptyline · Haloperidol · Psychotic depression - Delusional depression

\begin{abstract}
Although atypical antipsychotics are on the rise, traditional treatment of psychotic (or delusional) depression mostly includes the addition of classical antipsychotics to antidepressants. As there are only few data supporting this approach compared with antidepressant monotherapy, and almost no data comparing it with antidepressants of the latest generation, we conducted a retrospective chart analysis and a prospective, randomized open study on the efficacy and tolerability of nefazodone monotherapy versus combined treatment with amitriptyline and haloperidol in psychotic depression. The results suggest that the addition of classical antipsychotics should be reserved for those with very severe psychotic symptoms, but may not be needed in milder forms.
\end{abstract}

Copyright $\odot 2003$ S. Karger AG, Base

\begin{tabular}{ll}
\hline KARGER & ( ) 2002 S. Karger AG, Basel \\
0302-282X/02/0465-0031\$18.50/0 \\
$\begin{array}{l}\text { Fax +4161306 1234 } \\
\begin{array}{l}\text { E-Mail karger@karger.ch } \\
\text { www.karger.com }\end{array}\end{array}$ & $\begin{array}{l}\text { Accessible online at: } \\
\text { www.karger.com/nps }\end{array}$
\end{tabular}

\section{Introduction}

Psychotic (or delusional) depression is characterized by its greater severity, longer episodes, and greater incapacity compared with depression without psychotic features [1]. Since the landmark study of Spiker et al. [2], only few controlled trials have been published, and the appropriate pharmacological treatment of severe depression with psychotic features remains a controversial problem. The distinction between mood-congruent and moodincongruent features does not seem to imply a difference as far as the use of antipsychotics is concerned in clinical practice. Mood congruency of paranoid thoughts makes them an endogenous part of the depressive syndrome characterizing its severity. Thus, remission of depression through treatment with antidepressants should also ameliorate those psychotic symptoms. Nevertheless, classical antipsychotics are often added to antidepressants in clinical practice. Traditionally, a combination of tricyclics, e.g. amitriptyline (AMI) combined with haloperidol (HAL), is widely used, as these drugs are effective, well known to the practitioner and inexpensive. However, this combination may yield several disadvantages, exerting adrenergic, antihistaminergic, anticholinergic and, for HAL, antidopaminergic side effects.

Dr. H. Grunze

Psychiatrische Klinik der LMU

Nussbaumstrasse 7

D-80336 München (Germany)

Tel. +498951605335, Fax +498951605330, E-Mail grunze@psy.med.uni-muenchen.de 
Only few data exist so far on the use of selective serotonin-reuptake inhibitors (SSRIs) for the treatment of psychotic depression. A small trial of the combination of fluoxetine and perphenanzine suggested similar efficacy as the standard regimens tricyclic antidepressant (TCA) + antipsychotics or electroconvulsive therapy [3]. Interestingly, two trials with antidepressant monotherapy (sertraline vs. paroxetine [4] and venlafaxine vs. fluvoxamine [5]) also showed efficacy of monotherapy with these new antidepressants in delusional depression in a doubleblind and randomized design. However, it still remains unclear how a new antidepressant as a monotherapy would perform in comparison with the traditional combination therapy with a tricyclic and an antipsychotic.

Nefazodone (NEF) is a dual-acting serotonergic drug. Presynaptically, it inhibits serotonine reuptake and postsynaptically, it blocks 5-HT2 receptors. Its affinity to other receptors, i.e. alpha-adrenergic and cholinergic receptors, is very weak. This gives NEF a profile of high tolerability without side effects usually seen with classical TCAs. Alpha-1-related side effects, such as dry mouth, blurred vision or constipation, may be observed, but clearly less frequent than with its precursor trazodone or with TCAs, e.g. imipramine [6].

The efficacy of NEF in treating major depression appears comparable with typical SSRIs [7, 8] and established TCAs. Several studies comparing NEF with imipramine found equal efficacy [9-12]; the same holds true for another study versus AMI [13].

As mentioned, for psychotic depression, it is still controversial whether the addition of antipsychotics is really needed, especially as depression-triggering effects of classical antipsychotics have also been reported [14]. Similar to atypical antipsychotics, e.g. clozapine, olanzapine and risperidone, NEF also binds to the 5-HT2A receptor. Both agonist and antagonist binding to the 5-HT2A receptor finally result in a downregulation [15]. These preclinical data may imply that NEF not only has an intrinsic anxiolytic, but also antipsychotic action, probably making the addition of classical antipsychotics unnecessary.

The study described here was performed to test whether monotherapy with NEF achieves similar improvement of psychotic depression as standard treatment with AMI and HAL. Tolerability of these treatments was a secondary outcome parameter. The study consisted of two parts: first, we checked in a retrospective chart analysis whether there is sufficient evidence for comparable efficacy; next, we conducted an open, randomized prospective study in 20 inpatients allocating 10 to each treatment arm.

\section{Methods}

\section{Retrospective Chart Analysis}

This analysis was done using the records of 20 inpatients of the Departments of Psychiatry of the University of Munich and Freiburg, Germany, with the documented clinical diagnosis of psychotic depression and a Clinical Global Assessment Inventory (CGI) rating of at least 5 (markedly ill). In contrast to the prospective study, bipolarity was not an exclusion criterion. The allocation to treatment arms was random in so far that the last 10 admissions treated with either regimen (NEF vs. AMI-HAL) were chosen. Patients with a comedication other than short-term benzodiazepines for sleep disturbances or biperiden were excluded. Patients were treated on different wards of the hospital by different doctors according to their clinical needs, not with the intention of a study. However, as part of the hospital standard documentation system, the CGI was administered on a weekly basis. All patients had given their written consent at the entry to the hospital that data gathered during their stay can be used for post hoc scientific analysis.

Comparison was made between the documented CGI scores before treatment and after 4 weeks on either treatment.

\section{Prospective Open Study}

This 4-week, prospective trial was conducted in 20 adult inpatients of the Departments of Psychiatry of the University of Munich and Freiburg, Germany. Patients fulfilled the ICD-10 diagnostic criteria for severe depression with psychotic features (F32.3 or F33.3) and had a score of at least 25 on the Hamilton depression scale, 21-item version (HAMD [16]). Exclusion criteria were a psychiatric diagnosis different from F32.3 or F33.3, the need of continuous treatment with other antidepressants or mood stabilizer, electroconvulsive therapy during the last month, depot antipsychotics within the last 2 months, suicidality and medical comorbidity. The only comedication allowed during the 4-week trial were oxazepam and biperiden for the AMIHAL group. After giving their informed written consent, the patients were randomized on either treatment arm in the order of admission.

Treatment success was documented by the HAMD and the Brief Psychiatric Rating Scale (BPRS), and the respective values at the beginning and after 4 weeks were compared. Due to the small number of patients in both groups, the results are descriptive, but not statistically analyzed.

\section{Results}

\section{Retrospective Chart Analysis}

The NEF group consisted of 8 female and 2 male, the AMI-HAL group of 6 female and 4 male patients. Age was comparable between groups (mean $\pm \mathrm{SD}, 47 \pm 8.2$ for $\mathrm{NEF}, 49.2 \pm 7.5$ for AMI-HAL), as well as the mean number of previous depressive episodes (3.2 for NEF vs. 3.8 for AMI-HAL). Three patients in the NEF group were diagnosed as bipolar (F31.5), as well as 1 in the AMI-HAL group (31.4), but all of them were without a mood stabilizer during the observation period. This difference may be explained by the fact that clinicians consider it more hazardous to prescribe TCAs in bipolar depressed pa- 
Table 1. Results of the retrospective chart analysis a NEF group

\begin{tabular}{lllll}
\hline $\begin{array}{l}\text { Patient } \\
\text { No. }\end{array}$ & $\begin{array}{l}\text { ICD-10 } \\
\text { diagnosis }\end{array}$ & $\begin{array}{l}\text { NEF dosage } \\
\text { mg/day }\end{array}$ & $\begin{array}{l}\text { CGI } \\
\text { baseline }\end{array}$ & $\begin{array}{l}\text { CGI at } \\
\text { day } 28\end{array}$ \\
\hline 1 & 32.2 & 200 & 5 & 1 \\
2 & 32.3 & 400 & 7 & 5 \\
3 & 32.3 & 400 & 7 & 61 \\
4 & 31.5 & 350 & 7 & 3 \\
5 & 32.3 & 400 & 6 & 5 \\
6 & 32.2 & 400 & 6 & 4 \\
7 & 31.5 & 500 & 7 & 4 \\
8 & 31.5 & 400 & 7 & 4 \\
9 & 32.3 & 500 & 7 & 7 \\
10 & 32.3 & 400 & 7 & 6 \\
Mean \pm SD & & $395 \pm 83$ & $6.6 \pm 0.7$ & $4.5 \pm 1.7$ \\
\hline
\end{tabular}

b AMI-HAL group

\begin{tabular}{llllll}
\hline $\begin{array}{l}\text { Patient } \\
\text { No. }\end{array}$ & $\begin{array}{l}\text { ICD-10 } \\
\text { diagnosis }\end{array}$ & $\begin{array}{l}\text { AMI dosage } \\
\text { mg/day }\end{array}$ & $\begin{array}{l}\text { HAL dosage } \\
\text { mg/day }\end{array}$ & $\begin{array}{l}\text { CGI } \\
\text { baseline }\end{array}$ & $\begin{array}{l}\text { CGI at } \\
\text { day 28 }\end{array}$ \\
\hline 11 & 32.3 & 150 & 5 & 7 & 4 \\
12 & 32.3 & 150 & 8 & 7 & 5 \\
13 & 32.3 & 150 & 5 & 7 & 4 \\
14 & 32.2 & 75 & 2 & 6 & 4 \\
15 & 32.3 & 225 & 5 & 7 & 3 \\
16 & 32.3 & 150 & 5 & 7 & 7 \\
17 & 32.2 & 150 & 5 & 6 & 3 \\
18 & 32.3 & 225 & 10 & 7 & 6 \\
19 & 32.3 & 150 & 8 & 7 & 3 \\
20 & 31.4 & 75 & 3 & 5 & 4 \\
Mean \pm SD & & $150 \pm 50$ & $5.6 \pm 2.4$ & $6.6 \pm 0.7$ & $4.3 \pm 1.3$ \\
\hline
\end{tabular}

Premature discontinuation on day 14, LOCF. tients due to the high switch risk; however, none of the patients in either group had a switch during the observation period. Both NEF and AMI-HAL were dosed according to clinical needs, as patients were not part of a study during their individual treatment. The mean dosage of $\mathrm{NEF}$ at the endpoint of the analysis (day 28) was $395 \pm$ $83 \mathrm{mg} /$ day, the mean dosage of AMI $150 \pm 50 \mathrm{mg} /$ day, and of HAL $5.6 \pm 2.4 \mathrm{mg} /$ day.

Within 4 weeks, the mean of the CGI declined in the NEF group from $6.6 \pm 0.7$ (range 5-7) to $4.5 \pm 1.7$ (range 1-7) with last observation carried forward (LOCF) from one premature discontinuation. $6 / 10$ patients were considered as responders with a response criterion of a CGI improvement of at least 2 points (with all 3 bipolar patients being responders). One patient had the treatment stopped after 2 weeks due to strong sedation after little improvement (CGI decrease from 7 to 6 ).
For the AMI-HAL group, all patients remained for at least 4 weeks on this treatment. The mean of the CGI at the beginning was identical with the NEF group and declined from $6.6 \pm 0.7$ (range 5-7) to $4.3 \pm 1.3$ (range 3-7). $7 / 10$ patients were considered as responders with a response criterion of a CGI improvement of at least 2 points (with the 1 bipolar patient not responding sufficiently).

Table 1 shows the individual patient characteristics and treatment response.

\section{Prospective Open Study}

NEF or AMI-HAL were dosed at the clinicians' discretion and the daily dosage did not appear different from what was seen in the retrospective chart analysis. Two out of 10 patients of the NEF group discontinued prematurely after 1 and 2 weeks, respectively, 1 due to worsening of 
Table 2. Results of the prospective open study

\begin{tabular}{llllll}
\hline $\begin{array}{l}\text { Patient } \\
\text { No. }\end{array}$ & Medication & $\begin{array}{l}\text { HAMD } \\
\text { baseline }\end{array}$ & $\begin{array}{c}\text { HAMD } \\
\text { day } 28\end{array}$ & $\begin{array}{l}\text { BPRS } \\
\text { baseline }\end{array}$ & $\begin{array}{l}\text { BPRS } \\
\text { day } 28\end{array}$ \\
\hline 1 & NEF & 39 & 14 & 51 & 39 \\
2 & NEF & 30 & 7 & 43 & 23 \\
3 & NEF & 26 & 8 & 39 & 35 \\
4 & NEF & 27 & 17 & 44 & 32 \\
5 & NEF & 31 & 8 & 48 & 24 \\
$6^{1}$ & NEF & 25 & 31 & 41 & 48 \\
7 & NEF & 28 & 6 & 50 & 24 \\
$8^{2}$ & NEF & 24 & 11 & 38 & 34 \\
9 & NEF & 25 & 8 & 43 & 29 \\
10 & NEF & 25 & 10 & 43 & 37 \\
Mean \pm SD & & $28 \pm 4.5$ & $12 \pm 7.5$ & $44 \pm 4.4$ & $32.5 \pm 7.9$ \\
\hline 11 & AMI-HAL & 30 & 12 & 47 & 29 \\
$12^{3}$ & AMI-HAL & 35 & 24 & 62 & 46 \\
13 & AMI-HAL & 30 & 6 & 46 & 26 \\
14 & AMI-HAL & 35 & 28 & 53 & 45 \\
15 & AMI-HAL & 33 & 5 & 50 & 20 \\
$16^{2}$ & AMI-HAL & 30 & 21 & 43 & 35 \\
17 & AMI-HAL & 33 & 17 & 56 & 38 \\
18 & AMI-HAL & 41 & 19 & 52 & 32 \\
19 & AMI-HAL & 28 & 7 & 44 & 19 \\
20 & AMI-HAL & 32 & 10 & 55 & 20 \\
Mean \pm SD & & $32.7 \pm 3.7$ & $14.9 \pm 8.1$ & $50.8 \pm 6$ & $31 \pm 10$ \\
\hline 1 & LOCF, discontinuation after day 14. & & & \\
2 & LOCF, discontinuation after day 7. & & & \\
3 & LOCF, discontinuation after day 21. & & & \\
\hline & & & & & \\
\hline
\end{tabular}

symptoms, the other due to dizziness and nausea. In comparison, 3/10 patients of the AMI-HAL group were dropouts after 1, 2 and 3 weeks. The reasons included lack of efficacy and intolerable EPMS in 2 patients, and dry mouth and strong sedation in the third.

Again, both NEF and AMI-HAL were dosed according to clinical needs. The mean dosage of NEF at the endpoint of the analysis (day 28) was $425 \pm 45 \mathrm{mg} /$ day, the mean dosage of AMI $175 \pm 37$ and of HAL $7.2 \pm$ $4.4 \mathrm{mg} /$ day.

At baseline, patients in the AMI-HAL group were slightly more ill with an HAMD score of $32.7 \pm 3.7$ and a BPRS score of $50.8 \pm 6$ compared with $28 \pm 4.5$ (HAMD) and $44 \pm 4.4$ (BPRS) for the NEF group. Within 4 weeks, the mean of the HAMD in the AMI-HAL group declined to $14.9 \pm 8.1$ and in the NEF group to 12 \pm 7.5 with LOCF in the 5 patients with premature discontinuation. Defining a $50 \%$ reduction of the HAMD as sufficient treatment response, $8 / 10$ patients were responders in the NEF group and 6/10 in the AMI-HAL group.
Accordingly, the BPRS score declined to $31 \pm 10$ in the AMI-HAL group and to $32.5 \pm 7.9$ in the NEF group.

The individual results are shown in table 2. Figure 1 is a graphic depiction of the means of the HAMD and BPRS in both groups.

Oxazepam was rarely needed in both groups. Only 2 patients (1 in each group) received oxazepam for more than 3 days during the observation period. However, 4/10 patients in the AMI-HAL group needed biperiden $(4 \mathrm{mg} /$ day) for at least 14 days.

\section{Discussion}

The appropriate treatment of psychotic depression is still a controversial topic. Treatment habit is the addition of antipsychotics, often typical antipsychotics such as HAL. As NEF may have an intrinsic antipsychotic component of action by its 5-HT2A antagonism, we investigated whether it may be a candidate drug efficient enough 


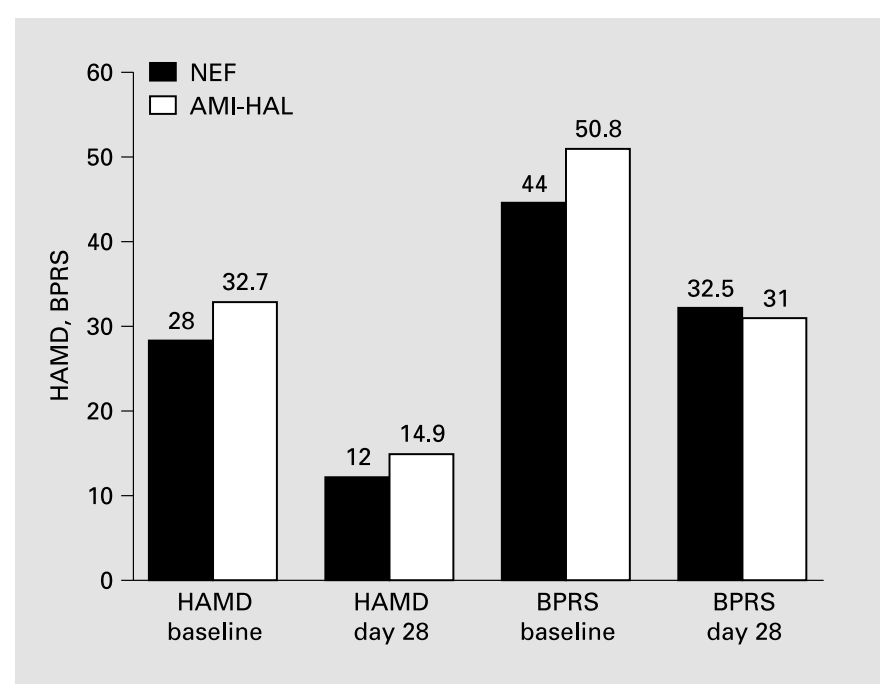

Fig. 1. Prospective comparison of NEF vs. AMI-HAL in psychotic depression. Results are LOCF for the dropouts ( 2 in the NEF group and 3 in the AMI-HAL group).

to treat psychotic depression without the addition of antipsychotics.

Both the retrospective chart analysis and the prospective open trial suggest that the overall efficacy of NEF is comparable with the one of the standard treatment with
AMI and HAL. From the point of view of tolerability, more dropouts were observed in the AMI-HAL group despite the allowed use of biperiden. However, due to the small number of patients, this may also be by chance.

Patients in the NEF group responded not as well for the BPRS score as they did for the HAMD. Analysis of the single items of the BPRS revealed that those items associated with psychotic features, item 4 (thought disorder), 10 (hostility), 11 (paranoia), 12 (hallucinations), and 15 (unusual thought content), responded less markedly than those focussing more on depressive symptoms and anxiety. Thus, in depression with severe and prominent psychotic features, the addition of antipsychotics to NEF still appears to be needed. When using HAL, it has to be kept in mind that NEF increases the area under curve for HAL plasma concentration by $36 \%$ after a one-time administration of HAL [17]. The pharmacological mechanism for this is not yet understood. However, in clinical practice, this means that HAL should be reduced when coadministered with NEF.

In conclusion, these data do not support a monotherapy approach towards psychotic depression with NEF as long as psychotic features are very prominent. For milder forms, an initial treatment with NEF monotherapy may be an adequate option.

\section{References}

1 Coryell W: The treatment of psychotic depression. J Clin Psychiatry 1998;59(suppl 1):2227.

2 Spiker DG, Weiss JC, Dealy RS, Griffin SJ, Hanin I, Neil JF, Perel JM, Rossi AJ, Soloff PH: The pharmacological treatment of delusional depression. Am J Psychiatry 1985;142: 430-436.

3 Rothschild AJ, Samson JA, Bessette MP, Carter-Campbell JT: Efficacy of the combination of fluoxetine and perphenazine in the treatment of psychotic depression. J Clin Psychiatry 1993;54:338-342.

4 Zanardi R, Franchini L, Gasperini M, Perez J, Smeraldi E: Double-blind controlled trial of sertraline versus paroxetine in the treatment of delusional depression. Am J Psychiatry 1996; 153:1631-1633.

5 Zanardi R, Franchini L, Serretti A, Perez J, Smeraldi E: Venlafaxine versus fluvoxamine in the treatment of delusional depression: A pilot double-blind controlled study. J Clin Psychiatry 2000;61:26-29.

6 Lader MH: Tolerability and safety: Essentials in antidepressant pharmacotherapy. $\mathrm{J}$ Clin Psychiatry 1996;57(suppl 2):39-44.
7 Baldwin DS, Hawley CJ, Abed RT, Maragakis BP, Cox J, Buckingham SA, Pover GH, Ascher A: A multicenter double-blind comparison of nefazodone and paroxetine in the treatment of outpatients with moderate-to-severe depression. J Clin Psychiatry 1996;57(suppl 2):4652.

8 Feiger A, Kiev A, Shrivastava RK, Wisselink PG, Wilcox CS: Nefazodone versus sertraline in outpatients with major depression: Focus on efficacy, tolerability, and effects on sexual function and satisfaction. J Clin Psychiatry 1996; 57(suppl 2):53-62.

9 Cohn CK, Robinson DS, Roberts DL, Schwiderski UE, O'Brien K, Ieni JR: Responders to antidepressant drug treatment: A study comparing nefazodone, imipramine, and placebo in patients with major depression. J Clin Psychiatry 1996;57(suppl 2):15-18.

10 Fontaine R, Ontiveros A, Elie R, Kensler TT, Roberts DL, Kaplita S, Ecker JA, Faludi G: A double-blind comparison of nefazodone, imipramine, and placebo in major depression. $\mathbf{J}$ Clin Psychiatry 1994;55:234-241.

11 Rickels K, Robinson DS, Schweizer E, Marcus RN, Roberts DL: Nefazodone: Aspects of efficacy. J Clin Psychiatry 1995;56(suppl 6):4346.
12 Rickels K, Schweizer E, Clary C, Fox I, Weise $\mathrm{C}$ : Nefazodone and imipramine in major depression: A placebo-controlled trial. Br J Psychiatry 1994;164:802-805.

13 Ansseau M, Darimont P, Lecoq A, De Nayer A, Evrard JL, Kremer P, Devoitille JM, Dierick M, Mertens C, Mesotten F, et al: Controlled comparison of nefazodone and amitriptyline in major depressive inpatients. Psychopharmacology (Berl) 1994;115:254-260.

14 Whitlock FA, Evans LE: Drugs and depression. Drugs 1978;15:53-71.

15 Smith RL, Barrett RJ, Sanders-Bush E: Adaptation of brain 5HT2 receptors after mianserin treatment: Receptor sensitivity, not receptor binding, more accurately correlates with behavior. J Pharmacol Exp Ther 1990;254:484488.

16 Hamilton M: Development of a rating scale for primary depressive illness. Br J Soc Clin Psychol 1967;6:278-296.

17 Barbhaiya RH, Shukla UA, Greene DS, Breul $\mathrm{HP}$, Midha KK: Investigation of pharmacokinetic and pharmacodynamic interactions after coadministration of nefazodone and haloperidol. J Clin Psychopharmacol 1996;16:26-34. 